\title{
SOME TWO-SIDED BOUNDING INEQUALITIES FOR THE BUTZER-FLOCKE-HAUSS OMEGA FUNCTION
}

\author{
Tibor K. POGÁNy AND H. M. SRIVASTAVA
}

\begin{abstract}
A new integral representation is obtained for the Butzer-Flocke-Hauss complete realargument Omega function $\Omega(x)$, which is closely associated with the complex-index Bernoulli function $B_{\alpha}(z)$ and with the complex-index Euler function $E_{\alpha}(z)$. Three two-sided bounding inequalities are given for this Omega function and their efficiency is also discussed.
\end{abstract}

Mathematics subject classification (2000): 33E20, 33E30, 34A30, 34A40.

Key words and phrases: Butzer-Flocke-Hauss complete omega function, Chaplygin type differential inequality, Chaplygin type comparison theorem, Dirichlet series, integral representation of the Omega function, Laplace integral representation of Dirichlet series.

\section{REFERENCES}

[1] M. Bertolino, Numerical Analysis, Naučna knjiga, Beograd, 1977 (in Serbo-Croatian).

[2] P. L. BUTZER, Bernoullifunctions, Hilbert-type Poisson summation formulae, partial fraction expansions, and Hilbert-Eisenstein series, in Analysis, Combinatorics and Computing, (T.-X. He, P. J.-S. Shiue and Z.-K. Li, Editors), Nova Science Publishers, Hauppauge, New York, 2002, 25-91.

[3] P. L. BUTZER, M. HAUSS, Applications of sampling theory to combinatorial analysis, Stirling numbers, special functions and the Riemann zeta function, in Sampling Theory in Fourier and Signal Analysis: Advanced Topics (J. R. Higgins and R. L. Stens, Editors), Clarendon (Oxford University) Press, Oxford, 1999, 1-37 and 266-268.

[4] P. L. ButZER, S. Flocke AND M. HAuSs, Euler functions $E_{\alpha}(z)$ with complex $\alpha$ and applications, in Approximation, Probability and Related Fields, (G. A. Anastassiou and S. T. Rachev, Editors), Plenum Press, New York, 1994, 127-150.

[5] P. L. Butzer, T. K. Pogány AND H. M. SRIVAStaVa, A linear ODE for the Omega function associated with the Euler function $E_{\alpha}(z)$ and the Bernoulli function $B_{\alpha}(z)$, Appl. Math. Lett., 19, (10) (2006), 1073-1077.

[6] D. S. Mitrinović, J. E. PeČArIĆ, Differential and Integral Inequalities, Matematički Problemi i Ekspozicije, 13, Naučna knjiga, Beograd, (1988) (in Serbo-Croatian).

[7] T. K. PogÁnY, H. M. SRIVASTAVA AND Ž. Tomovski, Some families of Mathieu a-series and alternating Mathieu a -series, Appl. Math. Comput., 173, (1) (2006), 69-108.

[8] H. M. Srivastava, Ž. Tomovski, Some problems and solutions involving Mathieu's series and its generalization, J. Inequal. Pure Appl. Math., 5, (2) (2004), Article 45, 1-13 (electronic). 